\title{
Exploring patient strategies in response to untoward healthcare encounters
}

\author{
Jelmer Brüggemann
}

Linköping University Post Print

Tweet

N.B.: When citing this work, cite the original article.

Original Publication:

Jelmer Brüggemann, Exploring patient strategies in response to untoward healthcare encounters, 2015, Nursing Ethics.

http://dx.doi.org/10.1177/0969733015591074

Copyright: SAGE Publications (UK and US)

http://www.uk.sagepub.com/home.nav

Postprint available at: Linköping University Electronic Press

http://urn.kb.se/resolve?urn=urn:nbn:se:liu:diva-124696 
EXPLORING PATIENT STRATEGIES IN RESPONSE TO UNTOWARD HEALTH CARE ENCOUNTERS

\section{ABSTRACT}

Background: Increasing attention to patients' rights and their ability to choose their health care provider have changed the way patients can respond to untoward, disempowering, and abusive health care encounters. These responses are often seen as crucial for quality improvement, yet they are little explored and conceptualized.

Objective: To explore patients' potential responses to untoward health care encounters, looking at their possible consequences for care quality improvement as well as for the individual patient.

Research design: The article is structured looking at two primary strategies: patient exit (leaving a health care provider) and patient voice (expressing grievances), derived from Hirschman (1970). These strategies were explored by the use of theoretical and empirical literature, and applied to an individual patient case. The case functions as a pedagogical tool to illustrate and problematize what exit and voice strategies can mean for a single patient. 
Ethical considerations: The patient case is my version of a generalized scenario that is described elsewhere. It does not represent an individual patient's story, but aims to be realistic and recognizable.

Findings and conclusions: Based on existing literature it is hypothesized that, in their current form, exit and voice strategies have a limited effect on care quality, and can come at a price for patients. However, both strategies may be of value to patients and providers. Therefore, the health care system could empower patients to engage in action, and could further develop ways for providers to effectively use patients' responses to improve practice and find ways to prevent patients from untoward experiences in health care.

Key words: patient voice, patient exit, quality of health care, patient dissatisfaction, untoward encounters, abuse in health care 


\section{INTRODUCTION}

Since World War II, health care providers have been giving increasing attention to the patients' perspectives on their care. ${ }^{1}$ This growing attention was at first mainly aimed at increasing patient compliance ${ }^{2}$ but later on such evaluations became valuable ends in themselves. ${ }^{1,2}$ In line with this, in political discourses the role of the patient has changed significantly over the past decades; patients are no longer seen as passive recipients of care, but instead an image of patients as active consumers of health care services has been introduced. The new active patient is a core concept in Western health care politics. ${ }^{3}$ For example, policy documents from the British Department of Health speak of consumerism in terms of patient choice and tailor-made solutions, ${ }^{4}$ and in Sweden the relatively new Act on system of choice in the public sector increases patients' freedom to choose a health care provider. ${ }^{5}$ These health care developments have changed the way patients can respond to untoward, disempowering and abusive encounters in health care. Despite the fact that patients' responses to such encounters are seen as crucial for quality improvement they are little explored and conceptualized.

The aim of the present article is to explore different strategies that a patient could use as a response to untoward encounters, and their possible consequences for quality of care in general as well as for the individual patient. Such an 
exploration could inform quality improvement discourses and their assumptions about patients' behaviour, in untoward encounters specifically.

\section{A MODEL OF EXIT AND VOICE}

Throughout the article I will use Hirschman's model of consumer strategies to respond to quality decline in providers as a conceptual framework. ${ }^{6}$ Hirschman distinguishes two main types of strategies: (a) exit: leaving a health care provider, and (b) voice: expressing concerns. These strategies are seen from the perspective of the relationship between the patient and provider and will be discussed as two conceptually separate strategies. In reality patients can combine these strategies, as in a "vociferous exit", or apply none at all, as in "passive acceptance". ${ }^{7}$ Exit and voice strategies are connected in subtle ways. First, there is probably a trade-off between the two strategies: more opportunities to voice will presumably increase the use of this strategy and reduce use of exit. ${ }^{6}$ Also, if exit is easy, e.g., if there are many other providers available and information is transparent, this will decrease the likelihood that patients will engage in voicing activities. This trade-off has been empirically confirmed in public service users, although it could not be fully confirmed for the health care sector. ${ }^{8}$ Second, the effects of exit strategies depend on the extent to which patients have a voice in medical encounters 
and can have a real demand for care. ${ }^{3}$ Exit and voice strategies are hence related in many ways but the separation serves an analytical and pedagogical purpose.

This article takes a case as a starting point, which I use as a pedagogical tool to illustrate and problematize what exit and voice strategies can mean for a single patient and to concretize general assumptions. The case description is my version of a scenario that a group of health care staff had created and worked with during a workshop about abuse in health care, and is described elsewhere. ${ }^{9,} 10$ The names are fictional and the description is generalized, not personal, but aims to be realistic and recognizable as something that could happen. For each strategy, after a short introduction, the potential consequences for care quality as well as for the individual patient will be explored through the use of both theoretical and empirical literature. However, the research area is difficult to demarcate and the research aim is explorative, which made a comprehensive literature review an endeavour beyond the scope of this study.

\section{CASE}

Anna is a middle-aged woman about to undergo a pelvic exam by gynaecologist Ingrid. Sophie, an auxiliary nurse at the women's clinic, will assist Ingrid during the exam. While Anna lies on the exam table, and rests her legs in the stirrups, Ingrid starts the exam. 
Some time into the exam Ingrid's phone rings. With little hesitation she takes off her gloves and answers her phone, while remaining seated between Anna's legs. Sophie, at first puzzled and later disturbed, chooses not to interfere. Anna starts to feel more and more uncomfortable, and feels objectified and ridiculed by Ingrid's behaviour.

\section{EXIT}

Exit strategies all share the characteristic that the patient somehow ceases to use a specific health care provider's services. These strategies are stimulated by choice-driven health care reforms that encourage patients to choose their health care provider. ${ }^{11}$ Building on market economic principles, it is assumed that exit is a strong signal of dissatisfaction and will function as an incentive to improve practice for underperforming providers. ${ }^{11}$ There is a growing body of knowledge about patients' willingness to choose their own providers, ${ }^{12,}{ }^{13}$ but even though patient choice is receiving growing attention in North-West Europe, a large review showed that patients often stay with their current provider. ${ }^{14}$

Little is known about the prevalence of patients' exit strategies, particularly following untoward encounters. In a study from the UK, as a response to experiencing dissatisfaction after specific events, about 7\% (59/860) changed from one NHS (National Health Service) provider to another, changed to private health care, 
ceased to use the service entirely, or obtained treatment abroad. Another $1 \%$ chose to use the service to a lower degree. ${ }^{15} \mathrm{~A}$ Swedish study showed that one out of four patients who had changed their primary care provider since the introduction of health care choice had done so because of dissatisfaction with how they were treated. ${ }^{16}$ Exit strategies have also been reported by patients who have experienced abuse in health care, by generally avoiding the healthcare system. ${ }^{17}$ In line with this, others have shown that a lack of trust in the health care provider is an important reason to exit. ${ }^{11,18}$

Possible consequences for care quality

In the phone call case, Anna could apply an exit strategy in different ways. She could choose to abort the examination and leave the room, she could choose to see another gynaecologist at her next visit, she could decide to leave the clinic completely and find a specialist at another hospital, or she could stop seeking care at all.

In Sweden, the "money-follows-the-patient-principle" is one way to increase providers' responsiveness to patients' exit, ${ }^{19}$ which otherwise can be low due to market restrictions. ${ }^{20}$ This would mean that if Anna chose to leave the clinic, the clinic would suffer financially. While this may not directly motivate Ingrid, it may motivate the head of the clinic who is responsible for the budget to make some changes. However, it is very questionable whether Ingrid or the clinic would know how to improve practice if 
Anna left the clinic without a trace. Exit alone supplies health care providers with very little information about the source of dissatisfaction. So even if there is an economic incentive to be responsive to patients' exit strategies, it is in no way guaranteed that providers will know how to respond. Related to this, a focus on exit may also hide dissatisfaction among patients who choose to stay or who cannot leave or switch, for which there can be many reasons. ${ }^{8}$ Economic incentives may also lose their effect on a provider's responsiveness if there is excess demand. ${ }^{11}$ If the women's clinic runs at maximum capacity in a situation of excess demand, then Anna's exit will mean that a new patient from a waiting list can enter the clinic; thereby not affecting the (economic) situation of the clinic at all. Summing up, patient exit as a mechanism for quality improvement in general can been criticised for a number of reasons and may not always have the effects desired in patient choice models. ${ }^{11,20}$

Possible consequences for the individual patient

Focus on patient exit can entail difficulties for the individual patient as it can harm valuable relationships. This is a development that may become increasingly problematic the more health care systems become fragmented. ${ }^{20}$ For Anna, receiving continuous care from Ingrid at the women's clinic may be of great value, especially if they have an on-going doctor-patient relationship and if she is highly dependent on Ingrid's care. 
Interpersonal continuity between physician and patient is not only associated with patient satisfaction, ${ }^{21}$ it also reduces hospitalisation and improves preventive care. ${ }^{22}$ On top of this, breaking a valuable relationship for Anna, as a patient, may be physically and emotionally difficult, ${ }^{20}$ especially if Anna needs continuous care. Unfortunately, little is known about whether those who "voted with their feet" were satisfied with their decision and were better off after the change. In a Swedish evaluation, a general tendency toward higher satisfaction in some patient groups who had switched was noted. ${ }^{16}$ It is even possible that Anna suffered so badly from the incident that she exited without seeking another provider in order to avoid a similar situation, which of course could have long-term health consequences.

If Anna experienced the situation as a traumatic event it may be of the utmost importance for Anna's health and safety to be able to exit or switch provider. In any case, an exit strategy may come at a high cost for her personal care without the guarantee that she will be better off elsewhere; that is, if she continues seeking health care.

\section{VOICE}

Voice is mostly recognized as a form of speaking up, an expression of one's dissatisfaction with the agents responsible for the service provided. Whereas exit is a 
straightforward action that requires little more than the possibility of leaving a provider, voice demands more from patients, who need to be willing to find a way to use the strategy, and providers, who need to develop effective channels through which patients can voice their concerns.

In health care, informal complaints, i.e. complaints not made through formal channels, seem to be the most widespread method to voice concerns. In a random Israeli population sample, $25 \%$ of the respondents reported having had a grievance, i.e. a reason to complain, during the last 12 months. ${ }^{23}$ However, only $9.5 \%$ had actually complained and a majority (75\%) had done so on a local level, instead of formally through official bodies. In a study in the UK, $38 \%$ of all people who had experienced a specific dissatisfying event, reported that they had had contact about this with a health care professional. ${ }^{15}$ But the fact that only $41 \%$ classified this contact as complaining makes prevalence numbers of complaints very unreliable. In a Swedish study, similar numbers were found, as more than half of the patients who had experienced abusive or ethically wrongful events had remained silent about this towards the health care system. ${ }^{24}$

Possible consequences for care quality 
In the phone call case, Anna has multiple options to voice her grievance: she can directly confront Ingrid (or Sophie for that matter) and explain what she is experiencing or question her behaviour; she can afterwards call or write to the head of the clinic; she can answer questionnaires sent out by the clinic; or she can file a complaint.

If Anna directly confronted Ingrid in the situation she could make Ingrid aware of how she was affected by the situation, and also give Ingrid the opportunity to consider what she could have done instead. Hearing directly from Anna could be a strong motivation for Ingrid to learn from the situation. However, this totally depends on Ingrid's competence and skills to implement feedback, ${ }^{25}$ and her definition of what is a mistake. ${ }^{26}$ If Ingrid acknowledged Anna's suffering, a feeling of regret might arise, which might lead to altered future behaviour and personal growth. ${ }^{27}$ This opportunity for learning may also come into being if Anna chose to write a letter to the head of the clinic, who in his or her turn would confront Ingrid. However, the impact of Anna's suffering on Ingrid's moral feelings is probably influenced by physical proximity. ${ }^{28}$

One major problem with informal complaints is that they remain unheard by the management, in contrast to formal complaints. ${ }^{23}$ Formal complaints can be used to drive quality improvement, e.g., if they are structurally analysed for special or common causes, ${ }^{29}$ but this can be problematic for several reasons. One reason is that patients, for various reasons, tend not to complain or file a malpractice claim about their 
grievances. ${ }^{30}$ A second reason is that complaints may not be concentrated enough, e.g., to develop targeted interventions at specific members of staff, ${ }^{31}$ although a recent study found that $3 \%$ of Australian doctors accounted for $49 \%$ of the formal complaints registered during 2000-2011.32

Besides complaining, Anna could also voice her concerns in patient surveys, but this might not lead to any changes in Ingrid's behaviour or at the clinic. One limitation of a satisfaction survey is that it often results in high scores on a broad range of caring aspects, thereby disguising specific untoward experiences. ${ }^{2,}$ 15, 33 Another limitation, which can be valid for other types of voice as well, is that surveys can identify improvement areas, but are not constructed to present how to improve these areas. If presented as a quality indicator, survey results can also function to inform other patients in their choice of provider. ${ }^{34}$ In a similar vein, other patients can be informed directly by (electronic) word-of-mouth. However, as long as others' choices are bound to the limitations of exit strategies, this information will have a limited effect on providers' performance. Opportunities for quality improvement could nevertheless be achieved if providers could transform potentially negative word-of-mouth reports into on-site complaints. $^{35}$

Possible consequences for the individual patient 
Voicing may also come at a high price for Anna. In particular, voicing her concern directly to Ingrid could be emotionally costly, considering power differences between patients and staff, patients' general fear of retribution, ${ }^{15}$ or of being seen as a troublesome patient. ${ }^{36}$ If, despite these barriers, Anna speaks up, Ingrid would be given a chance to repair the damage immediately. Unfortunately, Anna does not know the chances of this happening, and may have lost all confidence in Ingrid through the untoward incident itself. There is a risk that Anna will feel even more devastated if her voice is ignored or if staff respond with domination techniques. ${ }^{37}$ However, if Ingrid voices her regret, in return this can have a healing effect on Ingrid, ${ }^{27}$ as well as on Anna, as patients can feel relief when their feelings are confirmed. ${ }^{36}$ Regardless of whether the provider responds in a satisfactory way, any form of voicing probably serves a venting function for patients, i.e., it is a way to release distress. ${ }^{38}$ Besides having a venting function, voice directed towards other patients can also fulfil a patient's need to help or warn others. ${ }^{35,39}$ Some patients could benefit from sending a letter to the head of the clinic, or filing a written complaint, as expressive writing can lead to decreased anxiety. ${ }^{40}$

\section{DISCUSSION AND CONCLUSION}

Regarding quality improvement through patients' responses to untoward encounters, both voice and exit discourses build on a promise. Voice discourses, similar to patient 
involvement discourses, build on the promise that "professionals and care systems merely require reminding, or prompting, and good care will be forthcoming".$^{41, p .11}$ Exit discourses build on the promise that common problems in health care "will be solved through a natural coordination of the behaviour or choices of rational individuals" ${ }^{19,} \mathrm{p}$. 97 This explorative article identified some limitations to patients' strategies in response to untoward encounters that make these two promises look too optimistic. For patients, both strategies can be very costly, which can contribute to the high prevalence of silence and, most likely, acceptance strategies. However, as both voice and exit strategies can be of value to patients, there are incitements for health care systems to empower patients by reducing these costs, thereby also enabling patients to contribute to quality improvement. The limitations to patients' strategies explored in this article could also inform individual caregivers about the problem of relying too much on patients actions as a quality measure and of automatically interpreting patients' silence as a "false form of satisfaction". ${ }^{24, p .760}$ This emphasizes the need of not only empowering patients to use voice and exit strategies, but, e.g., also to educate staff to counteract abuse in health care. $^{42}$

In order to understand patients' behaviour and the implications of voice and exit strategies, patients' power in relation to their caregiver should be considered. Almost all patients are seeking help and are therefore at least to some extent dependent 
on their caregiver, creating a structural power imbalance in care encounters. It should also be considered that patients' possibilities to apply exit or voice strategies are related to constraints and resources related to gender, age, disability or ethnicity. Throughout this article, these aspects were not considered, but it does matter that Anna is a middleaged woman, whether Anna is able to speak the same language as Ingrid, and whether she is examined as part of a screening effort or as part of a cancer treatment. Only relying on certain patients' ability to express their concerns risks marginalizing or excluding others. Health care systems can differ in this aspect; in countries such as the UK and Sweden with a strong focus on equity of care, more explicitly for instance than in the US, quality improvement is very much also about the question of improvement for whom. Within such discourses it is of utmost importance to analyse whose exit and voice are included and used as a basis for quality improvement. In general, there certainly international differences in patients' opportunities for exit or voice, and how they are interdependent, but I believe Hirschman's model can be a useful conceptual framework to approach questions posed in this article in any health care system.

Related to a discussion on power relations is the disempowering aspect of the encounters explored in the current article, which in itself severely limits patients' possibilities to act. This shines a critical light on relying on patients' exit and voice behaviours as a uniform means for quality improvement. It is likely that specific aspects 
of patient care can be more easily improved than aspects that contributed to abusive and disempowering encounters. Consider for example aspects that patients find easier to identify, less taboo, easier to criticize, and where providers can make quick and apt changes based on complaints. It would be interesting in future research to study the diversity of patient strategies in relation to different aspects of care and their potential use for quality improvement.

Increasing attention on patients' possibilities to use voice and exit strategies theoretically runs the risk of putting Anna in a position where she is blamed if she cannot or chooses not to act. It has been suggested that complaining about dissatisfying encounters is seen by many as a moral imperative, and that not complaining is almost 'irrational'. ${ }^{15}$ Also, a focus on improvement through choice and exit has made some wonder whether patients may be held responsible if no improvements occur. ${ }^{19}$ It should not be demanded from patients that they engage in voice or exit strategies in order to receive good care, especially not if their initial vulnerable position is further weakened in untoward encounters. However, patient and provider benefits could be accomplished if patients are empowered and enabled to engage in such actions, while providers are aided to effectively use patients' responses to improve practice and find ways to prevent patients from experiencing situations like Anna did. 


\section{DECLARATION OF CONFLICTING INTERESTS}

The Author declares that there is no conflict of interest.

\section{FUNDING}

This work was supported by the Swedish Research Council (grant number 2011-2478). 


\section{REFERENCES}

1. Armstrong D. The patient's view. Soc Sci Med. 1984; 18: 737-44.

2. Williams B. Patient satisfaction: A valid concept? Soc Sci Med. 1994; 38:

509-16.

3. Batifoulier P, Domin JP and Gadreau M. Market Empowerment of the Patient: The French Experience. Rev Soc Econ. 2011; 69: 143-62.

4. Newman J and Vidler E. Discriminating customers, responsible patients, empowered users: consumerism and the modernisation of health care. J Soc Policy. 2006; 35: 193-209.

5. Ministery of Health and Social Affairs. Lag om valfrihetssystem (Act on System of Choice in the Public Sector [2008:962]) 2008.

6. Hirschman AO. Exit, voice, and loyalty: Responses to decline in firms, organizations, and states. Cambridge, Mass.: Harvard University Press, 1970.

7. Graham JW and Keeley M. Hirschman's loyalty construct. Employee Responsibilities and Rights Journal. 1992; 5: 191-200.

8. Dowding K and John P. The three exit, three voice and loyalty framework: a test with survey data on local services. Polit Stud. 2007; 56: 288-311.

9. Josephson A. Praktisk kunskap i att förhindra kränkningar - Rapport om dramapedagogiskt arbete med vårdpersonal [Practical knowledge in counteracting 
abuse in health care. Report on drama pedagogic work among health care staff]. Linköping: Division of Gender and Medicine, Faculty of Health Sciences, Linköping University, 2011.

10. Josephson A. Kunskap genom gestaltning och reflektion: om forumteater och forumspel som kunskapande handling [Knowledge through performance and reflection: About forum theatre and forum play as a knowledge producing act]. In: Burman A, (ed.). Konst och lärande : Essäer om estetiska lärprocesser [Art and learning: Essays about esthetic learning processes]. Huddinge: Södertörn University, 2014.

11. Tai-Seale M. Voting with their feet: patient exit and intergroup differences in propensity for switching usual source of care. J Health Polit Policy Law. 2004; 29: 491514.

12. Coulter A and Jenkinson C. European patients' views on the responsiveness of health systems and healthcare providers. Eur J Public Health. 2005; 15: 355-60.

13. Rosén $P$, Anell $A$ and Hjortsberg $C$. Patient views on choice and participation in primary health care. Health Policy. 2001; 55: 121-8.

14. Victoor A, Delnoij D, Friele R and Rademakers J. Determinants of patient choice of healthcare providers: a scoping review. BMC Health Serv Res. 2012; 12: 272. 15. Mulcahy $L$ and Tritter JQ. Pathways, pyramids and icebergs? Mapping the links between dissatisfaction and complaints. Sociol Health IIIn. 1998; 20: 825-47. 
16. The Swedish Agency for Health and Care Services Analysis. Vem har vårdvalet gynnat? [In Swedish: Who have benefitted from health care choice?]. Stockholm2013.

17. Schroll A-M, Kjærgaard $\mathrm{H}$ and Midtgaard J. Encountering abuse in health care; lifetime experiences in postnatal women-a qualitative study. BMC Pregnancy Childbirth. 2013; 13: 74.

18. Weitzman PF, Chang $G$ and Reynoso H. Middle-aged and older Latino American women in the patient-doctor interaction. J Cross Cult Gerontol. 2004; 19: 22139.

19. Fredriksson M. Is patient choice democratizing Swedish primary care? Health Policy. 2013; 111: 95-8.

20. Rodwin MA. The neglected remedy: Strengthening consumer voice in managed care. Am Prospect. 1997; 34: 45-50.

21. Saultz JW and Albedaiwi W. Interpersonal continuity of care and patient satisfaction: a critical review. Ann Fam Med. 2004; 2: 445-51.

22. Saultz JW and Lochner J. Interpersonal continuity of care and care outcomes: a critical review. Ann Fam Med. 2005; 3: 159-66.

23. Gal I and Doron I. Informal complaints on health services: hidden patterns, hidden potentials. Int J Qual Health Care. 2007; 19: 158. 
24.

Brüggemann AJ, Wijma B and Swahnberg K. Patients' silence following healthcare staff's ethical transgressions. Nurs Ethics. 2012; 19: 750-63.

25.

Wensing $M$ and Elwyn $\mathrm{G}$. Research on patients' views in the evaluation and improvement of quality of care. Qual Saf Health Care. 2002; 11: 153.

26.

Wijma B, Gustafsson LE, Thapar-Bjorkert S and Swahnberg K. What is an error? J Psychosom Obstet Gynaecol. 2005; 26: 233-35.

27.

Crigger NJ. Always having to say you're sorry: An ethical response to making mistakes in professional practice. Nurs Ethics. 2004; 11: 568-76.

28.

Peter E and Liaschenko J. Perils of proximity: a spatiotemporal analysis of moral distress and moral ambiguity. Nurs Inq. 2004; 11: 218-25.

29.

Hsieh SY. The use of patient complaints to drive quality improvement: an exploratory study in Taiwan. Health Serv Manage Res. 2010; 23: 5.

30. Kravitz R, Rolph J and McGuigan K. Malpractice claims data as a quality improvement tool. 1. Epidemiology of error in four specialties. JAMA. 1991; 266: 208792.

31. Kravitz R, Rolph J and McGuigan K. Malpractice claims data as a quality improvement tool. II Is targetting effective? JAMA. 1991; 266: 2093-7. 
32.

Bismark MM, Spittal MJ, Gurrin LC, Ward M and Studdert DM. Identification of doctors at risk of recurrent complaints: a national study of healthcare complaints in Australia. BMJ Qual Saf. 2013.

33. Williams B, Coyle J and Healy D. The meaning of patient satisfaction: an explanation of high reported levels. Soc Sci Med. 1998; 47: 1351-9.

34. Wensing $\mathrm{M}$ and Grol R. What can patients do to improve health care? Health Expect. 1998; 1: 37-49.

35. Hinz V, Drevs F and Wehner J. Electronic word of mouth about medical services. hche Research Paper. Hamburg, No. 2012/05: Hamburg Center for Health Economics, 2012.

36. Eriksson $U$ and Svedlund M. Struggling for confirmation--patients' experiences of dissatisfaction with hospital care. J Clin Nurs. 2007; 16: 438-46.

37. Brüggemann AJ and Swahnberg K. What Contributes to Abuse in Health Care? A Grounded Theory of Female Patients' Stories. Int J Nurs Stud. 2013; 50: 404-12. 38. Nyer PU. An investigation into whether complaining can cause increased consumer satisfaction. Journal of Consumer Marketing. 2000; 17: 9-19.

39.

Dobele A and Lindgreen A. Exploring the nature of value in the word-ofmouth referral equation for health care. Journal of Marketing Management. 2011; 27: 269-90. 
40.

Niles AN, Haltom KE, Mulvenna CM, Lieberman MD and Stanton AL. Effects of Expressive Writing on Psychological and Physical Health: The Moderating Role of Emotional Expressivity. Anxiety Stress Coping. 2013.

41. Sinding C, Miller P, Hudak P, Keller-Olaman S and Sussman J. Of time and troubles: Patient involvement and the production of health care disparities. Health. 2011.

42. Zbikowski A. Counteracting Abuse in Health Care from a Staff Perspective. Linköping, Sweden: Linköping University, 2014. 